\section{Measurement of Entrance Skin Dose and the Dose Received by Different Organs in Panoramic Dental Imaging}

\author{
Ahmadi A. ${ }^{\oplus}$, Negarestani A. ${ }^{2}$, Sina S. ${ }^{*}{ }^{\oplus}$, Sarshough S. ${ }^{4}$
}

\begin{abstract}
Background: Thermoluminescence dosimetry(TLD) has been known as one of the most effective methods for dose estimation in diagnostic radiology. Orthopantomogram (OPG) imaging is used by many dentists, oral and maxillofacial surgeons as an effective tool for choosing an appropriate treatment plan.
\end{abstract}

Objective: This study aims to measure the entrance skin dose and the dose values received by different head and neck organs in OPG imaging using TLD dosimeters (TLD-100).

Material and Methods: In this experimental study, the entrance skin dose and doses of various organs during imaging were measured by TLD dosimeters inside and on the surface of the Rando-Phantom. Doses to various organs, including thyroid, eye, esophagus, parotid and sublingual and submandibular salivary glands were measured. The measurements were repeated twice, and the dose values obtained in the two steps were compared.

Results: Based on the results obtained in this study, the minimum dose values were found in Esophagus; 65.81, and $59.31 \mu \mathrm{Gy}$, respectively. The maximum organ dose value was found for left parotid glands, 3842.42 , and 3399.58 for the two measurements, respectively.

Conclusion: The results show that the dose values can vary based on devices, exposure conditions, and TLD positioning.

Citation: Ahmadi A, Negarestani A, Sina S, Sarshough S. Measurement of Entrance Skin Dose and the Dose Received by Different Organs in Panoramic Dental Imaging. J Biomed Phys Eng. 2020;10(5):569-574. doi: 10.31661/jbpe.v0i0.878.

\section{Keywords}

Radiography; Panoramic; Thermoluminescent Dosimetry; Radiology; TLD100; Rando Phantom; Diagnostic Radiology

\section{Introduction}

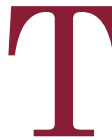
he precise measurement of entrance skin dose (ESD), in diagnostic radiology imaging is helpful in optimizing patient protection and developing standards and reference levels of diagnostic in countries. Many researchers in different countries have studied this parameter in various radiography imaging modalities [1-5]. In addition, risk assessment is not possible except by measuring the dose delivered to different organs. The International Committee for Radiation Protection (ICRP) suggests measuring the dose of various organs to evaluate the biological effects of radiation on the body [6]. Orthopantomogram (OPG) or panoramic dental imaging is widely used in forensic sciences $[7,8]$ and diagnostic radiology in diagnosis of various malformations of
${ }^{1} \mathrm{MSc}$, Kerman Graduate University of Advanced

Technology, Kerman,

Iran

${ }^{2} \mathrm{PhD}$, Kerman Graduate University of Advanced

Technology, Kerman,

Iran

${ }^{3} \mathrm{PhD}$, Radiation Research Center, Shiraz University, Shiraz, Iran ${ }^{4} \mathrm{PhD}$, Department of $\mathrm{Nu}$ clear Engineering, Shiraz University, Shiraz, Iran

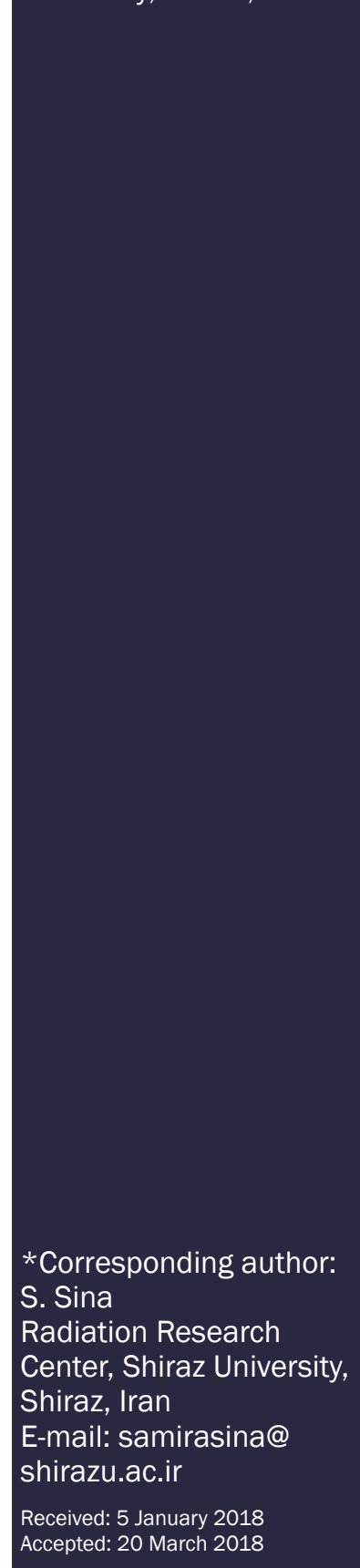


the head, jaw, and face, especially in orthodontic treatments; therefore, the dose reduction in these systems has been the subject of different investigations [7-11]. The children and adolescents dose reduction issue in diagnostic radiology has always been one of the main concerns in health physics science because of their higher radiation sensitivity $[12,13]$ and higher life expectancy than adults. Thus, measuring the dose delivered to patients in various radiographic tests and optimizing the image quality, and dose to reduce the risk of radiation exposure are very important. Thermoluminescence dosimetry has always been one of the effective dosimetry methods for estimating doses in diagnostic radiology, nuclear medicine and radiotherapy [14-20]. The purpose of this study is to estimate the entrance skin dose and the doses received by various organs in OPG imaging.

\section{Material and Methods}

\section{Determination of ECC of TLDs}

In this experimental study, cubic chips of T1D-100 (LiF, Mg, Ti) with dimensions of $1 \times 3 \times 3 \mathrm{~mm}^{3}$ were used for dose measurements. At first, a batch containing one hundred TLD-100 chips was selected for dosimetry. All TLDs were heated at $400{ }^{\circ} \mathrm{C}$ for 20 hours then at $80^{\circ} \mathrm{C}$ for 1 hour. The TLDs were then exposed to an equal value of dose; and the responses of these TLDs were read out using the Harshaw-4500 TLD reader device to obtain the ECC factor of the TLDs according to Equation (1).

$$
E C C_{i}=\frac{T L E}{\overline{T L E}}
$$

In which $\mathrm{ECC}_{\mathrm{i}}$ and $<\mathrm{TLE}_{\mathrm{i}}>$ are the element calibration coefficient and readout of TLD chip i, respectively, and $<\overline{T L E}>$ is the average readings of TLDs. After obtaining ECCs, 50 chips with ECCs close to 1 were selected to be used for dosimetry, and calibration.

\section{Calibration of TLDs}

In order to obtain the TLD calibration curve, 12 TLD chips in 4 plastic packs were used after annealing procedure ( 1 hour at $400{ }^{\circ} \mathrm{C}$ and 20 hours at $80{ }^{\circ} \mathrm{C}$ ). Three triple packs of these TLDs were exposed to specific doses of 416, 2190, and $5642 \mu \mathrm{Gy}$. A package was also used to measure background radiation. The calibration process was performed with an X-ray machine with the same X-ray quality of the OPG unit. Subsequently, all exposed chips were read out by the TLD reader, and the corrected readings of each chip (according to Equation 2 ) were used to plot the calibration curve.

$$
R_{i-C}=\left(\frac{R_{i}}{E C C_{i}}\right)-\left(\frac{\sum_{j=1}^{n}\left(\frac{R_{j-b}}{E C C_{j-b}}\right)}{n}\right)
$$

Where $R_{i-C}$ and $R_{i}$ are the primary readout and corrected readout of the $i^{\text {th }}$ chip. $R_{j-b}$ is the readout of the $\mathrm{j}^{\text {th }}$ background chip, $\mathrm{ECC}_{\mathrm{i}}$ and $\mathrm{ECC}_{\mathrm{j}-\mathrm{b}}$ are the ECC values of the TLD chip $\mathrm{i}$ and background chip j, respectively and, and finally, $\mathrm{n}$ is the number of TLDs assigned to the background measurement.

Since the calibration curve of TLDs is a linear curve, the relationship between the doses of each TLD and its corrected readings is as following:

$$
D_{i}(\mu G y)=\left[a \times R_{i-C}\right]
$$

Where $D_{i}(\mu G y)$ is the dose received by chip $\mathrm{i}$, and $\mathrm{a}$ is the calibration coefficient of TLDs.

\section{Dosimetry with TLD chips}

In this step, a number of annealed TLD chips were packed in dark plastic envelopes for measurement of the entrance skin dose of the Phantom. Several TLD chips were also placed within the Rando phantom at the position of the target organs (thyroid, eyes, esophagus, sublingual, and parotid, and submandibular salivary glands). Rando phantom was exposed with OPG device, with the routine exposure 
ESD and Organ Dose in Panoramic Dental Imaging

conditions used for the patients, i.e. $68 \mathrm{kv}$, $8 \mathrm{~mA}$, and $13.5 \mathrm{~s}$. The geometry of Rando phantom is shown in Figure 1. Three TLD chips were also used to measure background radiation. The exposed TLDs were read out by Harshaw 4500, TLD-reader. Considering the linear calibration curve, the dose received by each TLD was obtained according to equation (3). The whole process was repeated once more.

\section{Results}

The calibration curves obtained for the TLD100 in the two steps are shown in Figure 2. The dose of each TLD was obtained by multiplying the chip readout by calibration coefficient of each step, i.e. $68.72(\mu \mathrm{Gy} / \mathrm{nc}), 71.67$ $(\mu \mathrm{Gy} / \mathrm{nc})$ for the first, and the second steps, respectively. Figures $3 \mathrm{a}$ and $\mathrm{b}$ compare the dose in different organs obtained in the two steps. Table 1, a comparison of the entrance dose measured in each step is shown. The analysis of the TL dosimetry uncertainty is also shown in Table 2. In Table 3, there is a comparison

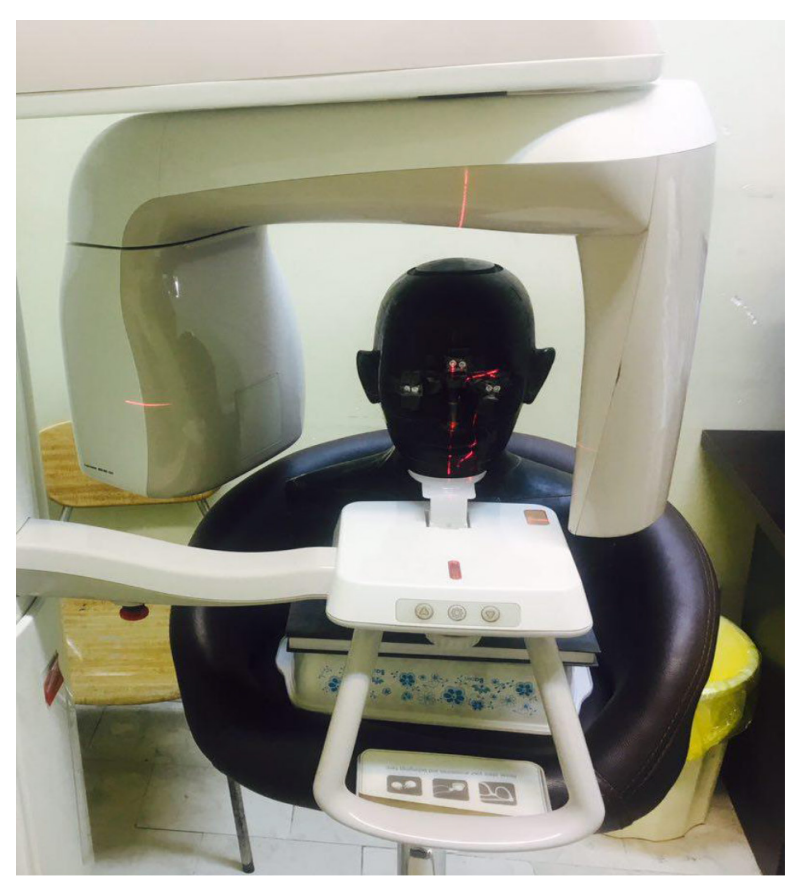

Figure 1: Imaging geometry of the measured values of entrance skin dose and organ doses in this study with the reported values in other investigations.

\section{Discussion}

According to the results shown in Figure 3, and Table 1, the results obtained in both measurements are comparable to each other. The small difference in the results may be due to the uncertainties in TLD, and positioning of the phantom. The total uncertainty in the TLD measurements is about $6 \%$. The uncertainty type-A of the TLD response due to the iteration of the measurements was $4 \%$, while type $\mathrm{B}$ uncertainty due to the calibration was $5 \%$. The errors due to the energy dependency of the TLDs were ignorable, as the energy spectrum used for the calibration was similar to energy spectrum used for the measurement. As the calibration TLDs, and those used for the measurement were read out at the same day, the uncertainty for fading of the TLD signals can be ignored.

\section{Conclusion}

It can be concluded the dose values can vary based on devices and exposure conditions. The difference observed between the doses values obtained in this study, and those reported by the previous investigators may be due to several reasons such as phantom positioning, the imaging technique, filtration of the $\mathrm{x}$ ray beam, and position of the dosimeters inside or on the phantom.

For instance, the large differences observed between the doses of thyroid, and parotid glands may mainly be because of the patient positioning (the parts of the head and neck which is irradiated as the main field size). Another reason for such differences may be because of the different position of the TLDs inside the organ.

Therefore, it can be concluded that we should put more TLD chips inside each organ, when we want to estimate the effective dose accurately. 
Ahmadi A. et al
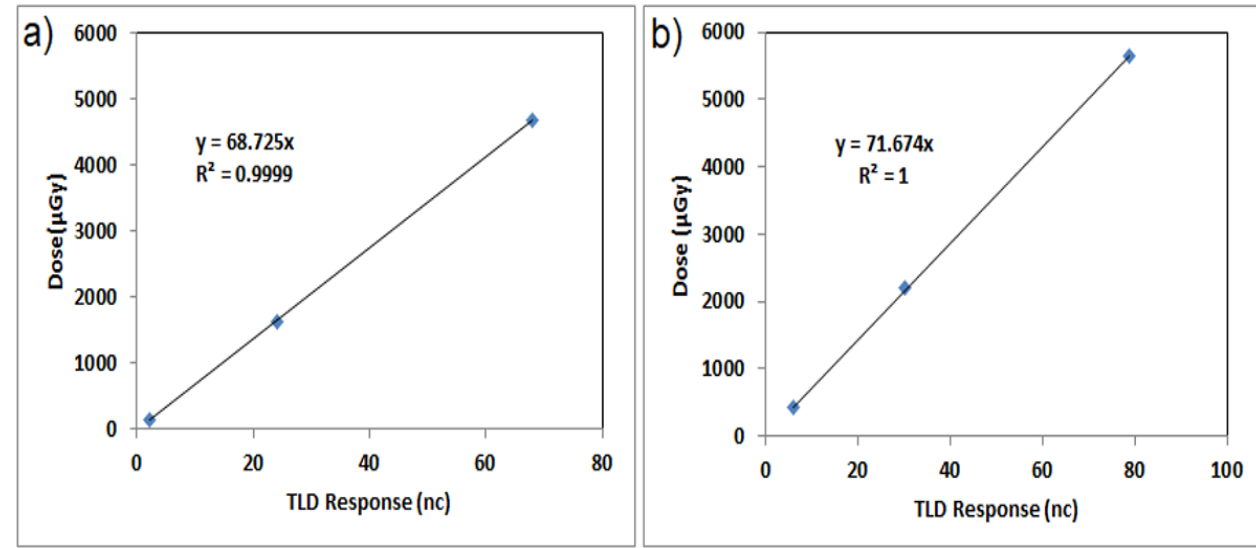

Figure 2: Thermoluminescence dosimetry (TLD) -100 calibration curve
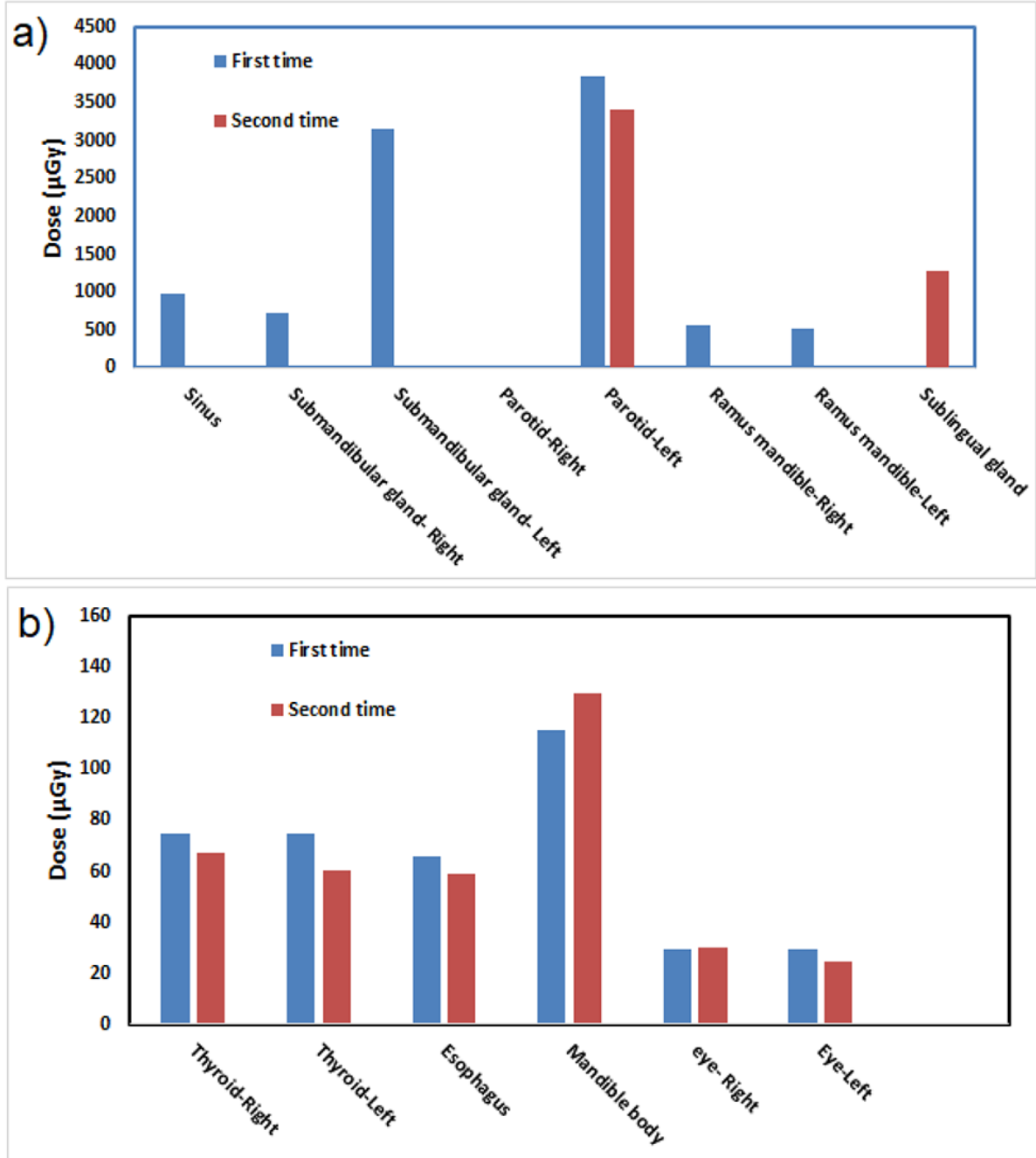

Figure 3: Comparison of absorbed dose of different organs in Orthopantomogram (OPG) imaging. 
ESD and Organ Dose in Panoramic Dental Imaging

Table 1: Entrance dose measured in each step

\begin{tabular}{ccc}
\multirow{2}{*}{ Organ } & \multicolumn{2}{c}{ Surface dose $(\boldsymbol{\mu G})$} \\
\cline { 2 - 3 } & Entrance skin dose( $\boldsymbol{\mu G})$ \\
\cline { 2 - 3 } & First time & Second time \\
\hline Right cheek & 79.55 \\
\hline Left cheek & 47.24 \\
\hline Temporal surface-Right & 11.15 \\
\hline Temporal surface-Left & 4.80 \\
\hline Head & 13.29 & \\
\hline Right back of the neck & & 360.58 \\
\hline Left back of the neck & & 334.28 \\
\hline Neck & 377.59 & \\
\hline Thyroid surface & & 52.68 \\
\hline Eye-Right & 29.25 & 30.00 \\
\hline Eye-Left & 29.79 & 24.98
\end{tabular}

Table 2: Thermoluminescence dosimetry error analysis of dosimeters

\begin{tabular}{lcc}
$\begin{array}{c}\text { Uncertainty } \\
\text { Component }\end{array}$ & Type A (\%) & Type B (\%) \\
\hline $\begin{array}{c}\text { Iteration of measure- } \\
\text { ments with TLDs }\end{array}$ & 4 & -- \\
\hline Dose Calibration & --- & 5 \\
\hline $\begin{array}{c}\text { Correction of energy } \\
\text { dependency }\end{array}$ & --- & -- \\
\hline $\begin{array}{c}\text { Correction for nonlin- } \\
\text { earity and fading }\end{array}$ & --- \\
\hline $\begin{array}{c}\text { Combination of errors } \\
\text { A-total }\end{array}$ & $\sigma_{\text {B-total }}=5$ \\
\hline Total error & $\sigma=\sqrt{\left(\sigma_{A}\right)^{2}+\left(\sigma_{B}\right)^{2}}=6.4$
\end{tabular}

Table 3: Comparison of measured doses in different investigations with the results of this study

This study $68 \mathrm{kv}, 8 \mathrm{~mA}$, $13.5 \mathrm{~s}$
Gavala [21] 66kV, $8 \mathrm{~mA}$
Eftekhari moghadam [22]

$70 \mathrm{Kv}, 10 \mathrm{~mA}, 14 \mathrm{~s}$

\begin{tabular}{cccc}
\hline Country & Iran & Athens & Iran \\
\hline Year & 2017 & 2009 & 2015 \\
\hline parotid & 3397.48 & 320 & 1825 \\
\hline thyroid & 46.75 & 60 & 1415 \\
\hline submandibular & 1572.50 & 416 & 1450 \\
\hline
\end{tabular}

360.58 Right back of neck;

334.28 Left back of neck

170 back of neck

Entrance skin

90 skin (occipital area)

Dose ( $\mu \mathrm{Gy}$ )

79.55 for right cheek

47.24 for left cheek

20 for skin (zygomatic area)

\section{Conflict of Interest}

\section{None}

\section{References}

1. Faghihi R, Mehdizadeh S, Sina S, Alizadeh FN, Zeinali B, Kamyab GR, et al. Radiation dose to neonates undergoing $X$-ray imaging in special care baby units in Iran. Radiat Prot Dosim etry. 2012;150(1):55-9. doi: 10.1093/rpd/ncr373. PubMed PMID: 22128357.
2. Sina S, Zeinali B, Karimipoorfard M, Lotfalizadeh F, Sadeghi M, Zamani E, Faghihi R. Investigation of the entrance surface dose and dose to different organs in lumbar spine imaging. J Biomed Phys Eng. 2014;4(4):119-26. PubMed PMID: 25599058. PubMed PMCID: PMC4289519.

3. Mettler Jr FA, Huda W, Yoshizumi TT, Mahesh M. Effective doses in radiology and diagnostic nuclear medicine: a catalog. Radiology. 2008;248(1):25463. doi: 10.1148/radiol.2481071451. PubMed 
PMID: 18566177.

4. Omrane LB, Verhaegen F, Chahed N, Mtimet S. An investigation of entrance surface dose calculations for diagnostic radiology using Monte Carlo simulations and radiotherapy dosimetry formalisms. Physics in Medicine \& Biology. 2003;48(12):180924. PubMed PMID: 12870585.

5. Duggan L, Warren-Forward H, Smith T, Kron T. Investigation of dose reduction neonatal radiography using specially designed phantoms and LiF:Mg,Cu,P TLDs. Br J Radiol. 2003;76(904):2327. PubMed PMID: 12711642.

6. International Commission on Radiological Protection. Recommendations of the International Commission on Radiological Protection. ICRP; 1991.

7. Baumann P, Widek T, Merkens H, Boldt J, Petrovic $A$, Urschler M, Kirnbauer B, Jakse N, Scheurer $E$. Dental age estimation of living persons: Comparison of MRI with OPG. Forensic science international. 2015;253:76-80. doi: 10.1016/j. forsciint.2015.06.001. PubMed PMID: 26093127.

8. Karaarslan B, Karaarslan ES, Ozsevik AS, Ertas E. Age estimation for dental patients using orthopantomographs. Eur J Dent. 2010;4(04):38994. PubMed PMID: 20922158. PubMed PMCID: PMC2948737.

9. Danforth RA, Clark DE. Effective dose from radiation absorbed during a panoramic examination with a new generation machine. Oral Surg Oral Med Oral Pathol Oral Radiol Endod. 2000;89(2):236-43. PubMed PMID: 10673663.

10. Ludlow JB, Davies-Ludlow LE, Brooks SL. Dosimetry of two extraoral direct digital imaging devices: NewTom cone beam CT and Orthophos Plus DS panoramic unit. Dentomaxillofacial Radiology. 2003;32(4):229-34.

11. Gijbels F, Sanderink G, Wyatt J, Van Dam J, Nowak $B$, Jacobs R. Radiation doses of indirect and direct digital cephalometric radiography. Br Dent J. 2004;197(3):149-52. PubMed PMID: 15311250.

12. Gavala S, Donta C, Tsiklakis K, Boziari A, Kamenopoulou V, Stamatakis HC. Radiation dose reduction in direct digital panoramic radiography. Eur J Radiol. 2009;71(1):42-8. doi: 10.1016/j. ejrad.2008.03.018. PubMed PMID: 18448296.

13. Tsiklakis K, Donta-Bakoyanni C, Tassopoulou M, Kamenopoulou V. Absorbed radiation dose during lateral cephalometric radiography: comparison of screen-film systems and field-size combinations. J Clin Pediatr Dent. 2000;24(2):117-21. PubMed PMID: 11314319.
14. Sina S, Faghihi R, Meigooni AS, Mehdizadeh S, Mosleh Shirazi MA, Zehtabian M. Impact of the vaginal applicator and dummy pellets on the dosimetry parameters of Cs-137 brachytherapy source. J Appl Clin Med Phys. 2011;12(3):3480. PubMed PMID: 21844861. PubMed PMCID: PMC5718639.

15. Mosleh Shirazi MA, Faghihi R, Siavashpour Z, Nedaie HA, Mehdizadeh S, Sina S. Independent evaluation of an in-house brachytherapy treatment planning system using simulation, measurement and calculation methods. J Appl Clin Med Phys. 2012;13:103-112. doi: 10.1120/jacmp.v13i2.3687. PubMed PMID: 22402384. PubMed PMCID: PMC5716415.

16. Mohammadyari P, Zehtabian M, Sina S, Tavasoli AR, Faghihi R. Dosimetry of gamma chamber blood irradiator using PAGAT gel dosimeter and Monte Carlo simulations. J Appl Clin Med Phys. 2014;15(1):316-30. doi: 10.1120/jacmp. v15i1.3952. PubMed PMID: 24423829. PubMed PMCID: PMC5711240.

17. Sadeghi M, Sina S, Faghihi R. Investigation of LiF, $\mathrm{Mg}$ and Ti (TLD-100) Reproducibility. J Biomed Phys Eng. 2015;5(4):217-222. PubMed PMID: 26688801. PubMed PMCID: PMC4681467.

18. Ghaedizirgar M, Faghihi R, Paydar R, Sina S. Effective Dose in Two Different Dental Cbct Systems: Newtom Vgi and Planmeca 3d Mid. Radiation Protection Dosimetry. 2017;179(3):287-293. doi: 10.1093/rpd/ncx008.

19. Zehtabian M, Dehghan N, Danaei Ghazanfarkhani M, Haghighatafshar M, Sina S. Measurement of the Dose to the Family Members Taking Care of Thyroid Cancer Patients Undergoing l-131 Therapy in Nuclear Medicine Using TLD-100. Radiat Prot Dosimetry. 2017;174(4):541-544. doi: 10.1093/ rpd/ncw242. PubMed PMID: 27555655.

20. Moudi E, Hadian H, Monfared A, Haghanifar S, Deilam G, Bahemmat N. Assessment of radiation exposure of eyes, parotid and thyroid gland during panoramic radiography. World Journal of Medicine and Medical Science Research. 2013;1(3):44-50.

21. Gavala S, Donta C, Tsiklakis K, Boziari A, Kamenopoulou V, Stamatakis HC. Radiation dose reduction in direct digital panoramic radiography. Eur J Radiol. 2009;71(1):42-8. doi: 10.1016/j. ejrad.2008.03.018. PubMed PMID: 18448296.

22. Moghadam AE, Mardani M, Hasanzadeh H, Rafati $M$. Assessment of absorbed dose in critical organs in OPG: a phantom study. Journal of Paramedical Sciences (JPS). 2015;6(1):44-9. doi: 10.22037/ jps.v6i1.8183. 